Atmos. Chem. Phys., 3, 2147-2159, 2003

www.atmos-chem-phys.org/acp/3/2147/

\title{
Characterization of African dust over southern Italy
}

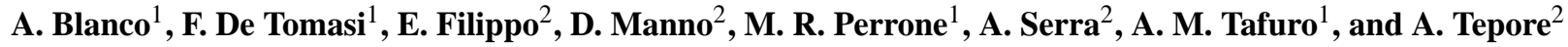 \\ ${ }^{1}$ Istituto Nazionale di Fisica della Materia, Dipartimento di Fisica, Universita' di Lecce, Lecce, Italy \\ ${ }^{2}$ Istituto Nazionale di Fisica della Materia, Dipartimento di Scienza dei Materiali, Universita' di Lecce, Lecce, Italy
}

Received: 1 July 2002 - Published in Atmos. Chem. Phys. Discuss.: 2 September 2003

Revised: 11 November 2003 - Accepted: 24 November 2003 - Published: 4 December 2003

\begin{abstract}
Dust samples from rainfall residues have been collected in southeast Italy $\left(40^{\circ} 20^{\prime} \mathrm{N}, 18^{\circ} 6^{\prime} \mathrm{E}\right)$ during dust outbreaks occurred from April to June 2002 to characterize morphological and elemental particle composition by different techniques, and investigate the dependence of particle properties on source regions. Four-day analytical back trajectories and satellite images have been used to infer source regions of the investigated dust samples.

It has been found that the TOMS absorbing aerosol index was in the range $0.7-2.2$ over Southern Italy when samples have been collected. The particle-size and -shape analysis by a scanning electron microscope (SEM) has revealed either that the particle-diameter distribution was between 0.3 and $30 \mu \mathrm{m}$ with median-diameter values between $1.7-2.4 \mu \mathrm{m}$, and that the particles were characterized by a roundness factor varying from 0.8 to 2.5 . The infrared transmission spectra have allowed recognizing that all dust samples contained a significant amount of illite. The X-ray energy dispersive (EDX) measurements have revealed that the $\mathrm{Al} / \mathrm{Si}$ ratio of the transported dust varies from 0.41 to 0.50 , and that the $\mathrm{Al} / \mathrm{Si}$, $\mathrm{Ca} / \mathrm{Al}, \mathrm{K} / \mathrm{Ca}$, and $\mathrm{Fe} / \mathrm{Ca}$ ratios differ according to source regions and therefore can be used as indicators of dust source regions. Indeed, it has been found that dust samples with larger $\mathrm{Ca} / \mathrm{Al}$ and $\mathrm{Si} / \mathrm{Al}$ ratios and lower $\mathrm{Fe} / \mathrm{Ca}$ and $\mathrm{K} / \mathrm{Ca}$ ratios, have been collected along dust events with a source region in northwestern Sahara. On the contrary, the samples collected along dust events with the origin mainly in Chad, Niger, Algeria and Lybia were characterized by larger $\mathrm{Fe} / \mathrm{Ca}$ and $\mathrm{K} / \mathrm{Ca}$ ratios.
\end{abstract}

Correspondence to: M. R. Perrone

(perrone@le.infn.it)

\section{Introduction}

Mineral aerosols absorb at ultraviolet, visible and infrared wavelengths and the scientific community is making great efforts to document and understand their interactions with the environment, since the magnitude of their radiative forcing and climate impact is still largely uncertain (e. g. Sokolik and Toon, 1999; Intergovernmental Panel on Climate Change, IPCC, 2001). The most widespread mineral aerosols are those originating from wind erosion of arid and semi-arid lands and the global source strength of these aerosols is currently estimated to a value between 1000 and $5000 \mathrm{Mt} / \mathrm{yr}$ (Tegen and Fung, 1995). The Sahara desert represents one of the main sources of mineral aerosols and it is considered to be the dominant dust source for the Mediterranean basin. The dust particles captured by the wind at the surface are raised to considerable tropospheric altitudes by the strong convective regimes that develop over the desert, and then are transported by the winds to Europe and Middle East regions, and over the North Atlantic Ocean up to South America. Dust particles originating from Sahara have been observed over southern Europe (e.g. Prodi and Fea, 1979; Levin et al.,1980; Guerzoni et al., 1997; Avila et al., 1997; Gobbi et al., 2003), in the Caribbean (e.g. Talbot et al., 1986), and southern Florida (e.g. Prospero, 1999). However, only a small fraction of the total soil loss in Northern Africa reaches Europe (Molinaroli, 1996). In particular, d'Almeida (1986) has shown that the dust transport across the northern borders of the Sahara into the west Mediterranean Sea is approximately $12 \%$ of the total, mainly originating from Morocco to north Mauritania (Source 1), south Algeria, Mali, and Niger(Source 2), south Libya and Chad (Source 3), and Egypt and the northern part of Sudan (Source 4). The location of Source 1-4 is shown in Fig. 1a by dots (from D'Almeida, 1986). The arrows in Fig. 1a indicate the main routes of dust outbreaks toward the Mediterranean Sea and continental Europe (from Molinaroli, 1996). 


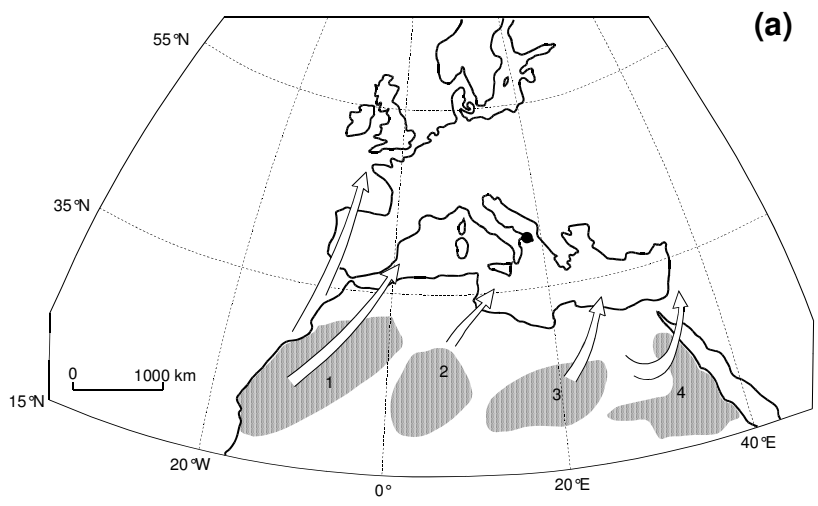

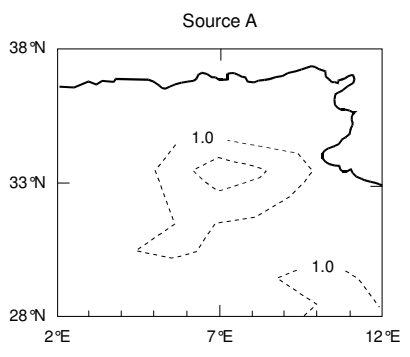

(b)

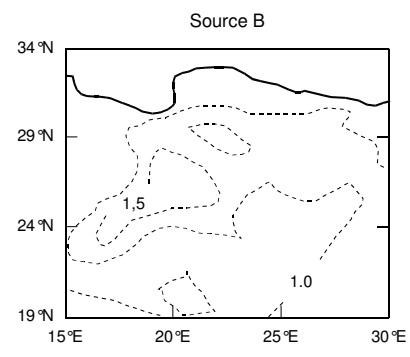

(c)
Fig. 1. (a) The map shows the location of the collection site (full dot). Shared areas 1 to 4 represent the most productive sources of Saharan dust (from d'Almeida, 1986). Source 1: Morocco to north Mauritania; source 2: south Algeria, Mali and Niger; source 3: south Libya and Chad; source 4: Egypt and north Sudan. Arrows indicate the main routes of dust outbreaks toward the Mediterranean sea and continental Europe (from Molinaroli, 1986). (b) The map shows the persistently active region located to the south of the northern (Tell) Atlas Mountains (from Prospero et al., 2002). (c) The map shows the dust area extending over the eastern Libyan desert into western Egypt (from Prospero et al., 2002).

Data from the Total Ozone Mapping Spectrometer (TOMS) sensor on the Nimbus 7 satellite have recently been used by Prospero et al. (2002) to map the global distribution of major atmospheric dust sources. In particular, the TOMS absorbing aerosol index (AAI) over a 13-year period (1980-1992) has been examined for evidence of persistent dust sources. The TOMS AAI depends on the relative concentration of UV absorbing (smoke and dust) aerosol particles and varies between 0 and 4 over land and water (Herman et al., 1997). It has been observed by Prospero et al. (2002) that the most active TOMS dust sources are associated with topographic lows or are situated in close proximity to mountains and highlands and two more dust sources have been identified in north Africa, with respect to those classified by d'Almeida (1986). The first persistently active region (Source A) is located to the south of the northern (Tell) Atlas Mountains (Fig. 1b) while, the second (Source B) is a large area extending over the eastern Lybian desert into western Egypt (Fig. 1c). Selected monthly mean TOMS AAI are shown as isolines in Fig. 1b and Fig. 1c, respectively (from Prospero et al., 2002). In particular, mean AAI values of April 1986 and March 1986 are plotted in Fig. 1b and Fig. 1c, respectively.

The desert dust properties may change as the particles move away from source regions and dust particles studies at different monitoring sites are of peculiar importance to know about processes affecting levels and compositions of mineral aerosols. A study by Prospero et al. (1981) has shown the changes in mineralogy of Sahara dust samples collected at various distances off the coast of Africa along the dust plume transported over the Atlantic Ocean. Chester et al. (1992) have reported the variation of clay minerals with latitude in dust samples collected off the west coast of Africa. On the contrary, a recent study of Chiapello et al. (1997) based on 3 years of daily measurements of mineral dust concentrations at Sal Island (Capo Verde), has revealed that the differences in dust composition allow getting a clear signature between the different source regions involved since can be related to soil composition changes over the North African desert (Avila et al., 1997).

The transport of Saharan dust over northern and western Italy has been documented and studied from the meteorological, mineralogical and chemical points of views in several papers (Prodi and Fea, 1979; Bergametti et al., 1989a, b; Guerzoni et al., 1997, Molinaroli, 1996). Lidar and in situ observations of Saharan aerosols for the analysis of the particle optical and physical properties have recently been reported by Gobbi et al. (2003).

This work is an attempt to trace source regions and transport of dust plumes by means of grain-size and elemental particle composition analyses performed on dust samples collected at Lecce, a new monitoring site $\left(40^{\circ} 20^{\prime} \mathrm{N}, 18^{\circ} 6^{\prime} \mathrm{E}\right)$ in the south-eastern corner of Italy, which is $800 \mathrm{~km}$ away from the northern Africa coast. It is believed that the results of this paper contribute to the studies on the dependence of the desert aerosol properties on source regions and monitoring site. The dust samples have been collected during strong dust outbreaks occurred from April to June 2002. Climatological studies of the desert aerosol transport to the Mediterranean based on satellite and ground-based observations have shown that the dust input is maximum in late spring and summer, when the most common configuration of cyclones favors northward motion of the air masses (e.g. Alpert et al., 1990). The 11 years of daily Meteosat ISCCP-B2 VIS images have recently been used by Moulin et al. (1998) to get a comprehensive analysis of the African dust transport in the Mediterranean atmosphere and a marked annual cycle of the dust transport has also been revealed by the satellite images: it begins in spring over the eastern basin, is maximum in summer over the western and central basins, and strongly decreases during autumn and winter. These patterns are shown to be related to both cyclogenesis over North Africa and rainfall over the Mediterranean Sea. It is worth observing that the wind fields generated under such meteorological conditions 
can be rather complex and as a consequence a multilayered dust transport might occur over the Mediterranean (Hamonou et al., 1999).

Modelled back trajectories, satellite data and true color SeaWiFS images have been used in this paper to document and characterize the dust events during which dust samples have been collected.

Sampling methods and satellite data used to characterize the investigated dust events are given in Sects. 2 and 3, respectively. Results and discussion are presented in Sect. 4. Summary and conclusion are in Sect. 5.

\section{Sampling site and methods}

The dust samples have been collected at the Physics Department of Lecce's University. A rural site quite isolated from local anthropogenic or soil-derived contamination, which is located on the flat Salentum peninsula, at about 15 and $25 \mathrm{~km}$ from the Adriatic and Ionic Sea, respectively, and at about $800 \mathrm{~km}$ from the northern Africa coast. This last peculiarity makes the sampling site rather suitable for the monitoring of African dust transport early in its life cycle. The desert type aerosols can be directly advected to Lecce from the African deserts without being significantly affected by antropogenic aerosols and by the removal of coarse mode particles with diameters $>1 \mu \mathrm{m}$ as a consequence of the gravitational setting (e.g. Sokolik and Toon, 1999; Mattis et al., 2002).

Several rain samples have been collected during every dust event on rectangular glass pans of about $25 \times 40 \mathrm{~cm}^{2}$ set at about $5 \mathrm{~m}$ from ground. The rain collectors have been exposed only during rainfall and the typical sampling duration was of 6-8 h. Care was taken to avoid the contamination by local sources as dust like particles both during the sampling duration and before the sample processing time. The dust samples from rainfall residues have been processed few days after the collection day. However, it has been observed that the results on sample characterization were not dependent on the time elapsed between collection and processing. We have examined the composition of these samples qualitatively by two methods. The first method was infrared transmission spectroscopy, using the conventional $\mathrm{KBr}$ pellet technique with a Perkin Elmer Spectrum 2000 FT-IR spectrometer in the $1.5-26 \mu \mathrm{m}$ spectral region. To this purpose about $0.05-$ $0.3 \%$ by mass of the dust taken away from the glass substrate has been embedded in $250 \mathrm{mg}$ of powder of potassium bromide $(\mathrm{KBr})$, which is transparent in the spectral range of interest. This method produces a transmittance spectrum that can provide qualitative information on the major chemical constituents in the sample. Then, micro-analytical methods have been used to simultaneously detect morphology and elemental composition of every single particle. Atmospheric particles are chemically and morphologically heterogeneous and the average composition obtained by bulk analysis does not highlight the single particle characteristics. Single parti-
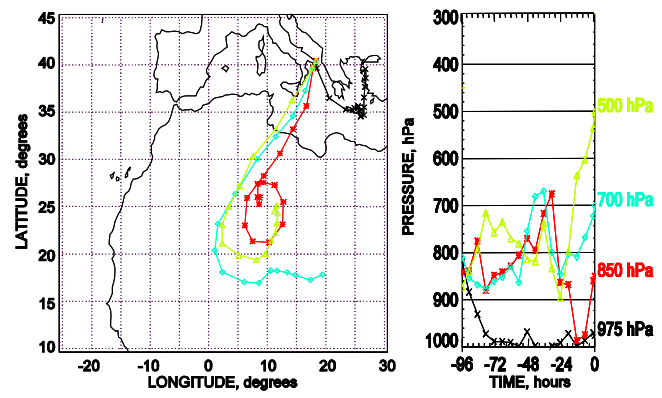

(a) $12 / 04 / 02$
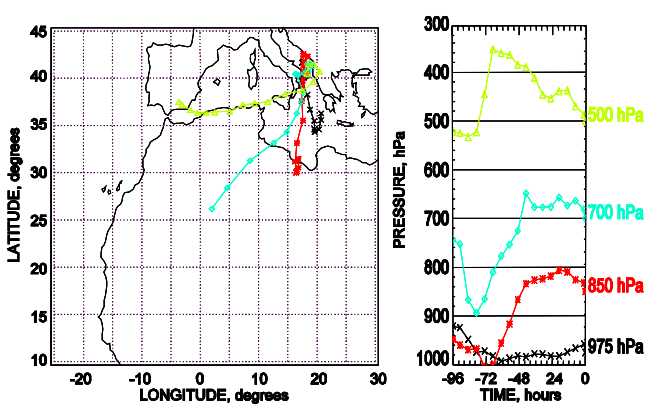

(b) $13 / 05 / 02$
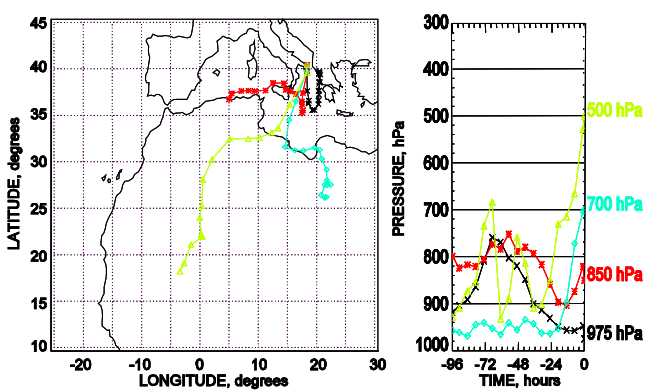

(c) $24 / 05 / 02$
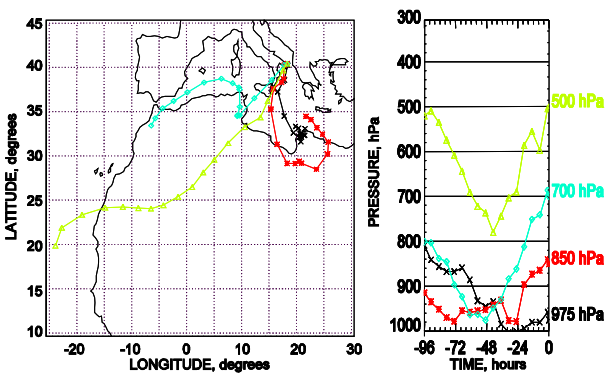

(d) $07 / 06 / 02$

Fig. 2. Four-day analytical back trajectories for the 13:00 UT arrival time and for the $975,850,700$, and $500 \mathrm{hPa}$ arrival height.

cle studies are essential in environmental atmospheric chemistry, since allow identifying the various processes involved in the formation and evolution of atmospheric aerosols (Raes et al., 2000; Ro et al., 2001).

In our study, morphological and elemental composition analyses have been performed using a scanning electron microscope SEM-JEOL JSM 5010LV equipped with an Oxford X-ray energy dispersive (EDX) microanalysis system. To this end, the dust has been deposited onto SEM sample holders covered with a carbon adhesive layer. 


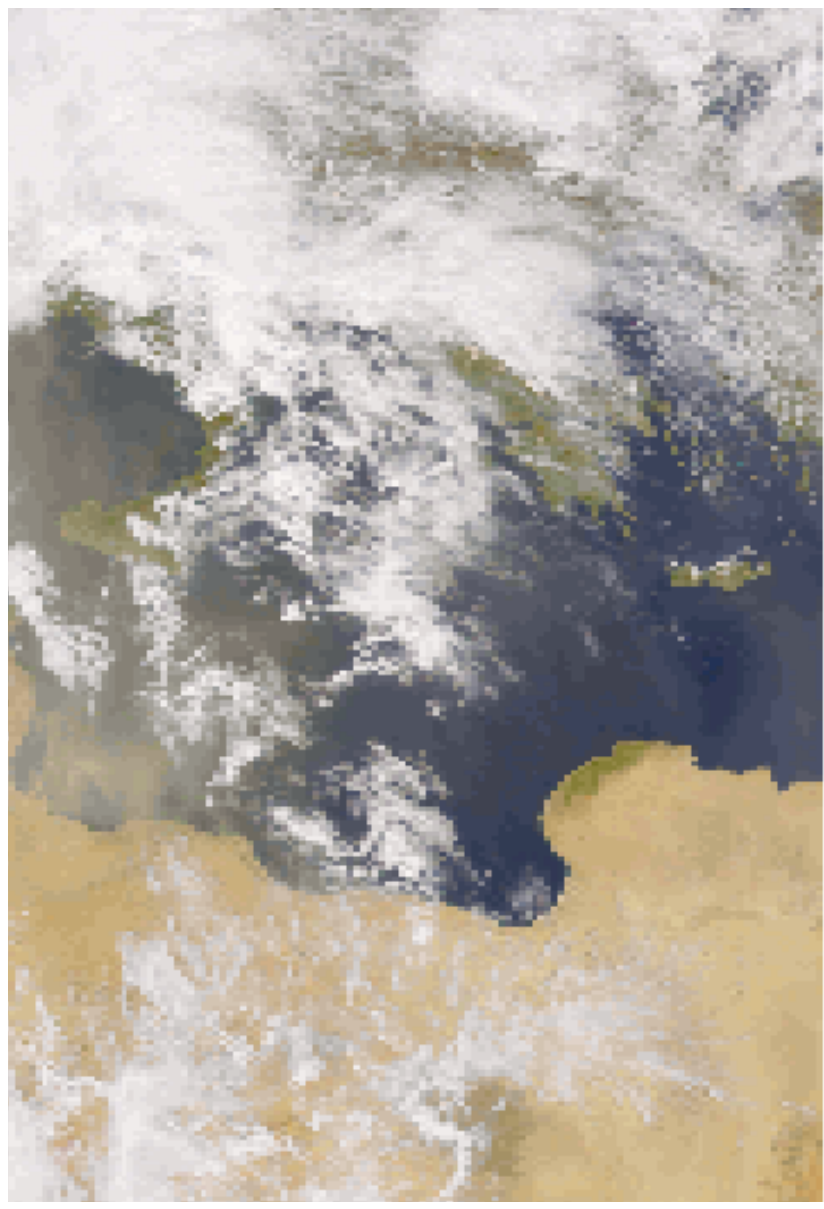

Fig. 3. SeaWiFS image taken on 11 April, 2002 over the Mediterranean Sea and southern Italy.

The SEM-EDX system can provide single particle surface morphology, size and shape distribution and elemental composition qualitatively and semi-quantitatively, even of low atomic number elements, such as $\mathrm{C}$ and $\mathrm{O}$. However, it has the disadvantage of being very time consuming. Furthermore, accurate quantitative estimates can be hampered by the loss of volatile components, since the dust particles are subjected to high vacuum conditions $\left(10^{-6}\right.$ Torr $)$ and an intense electron beam during SEM EDX analyses (Ma et al., 2001). SEM images have been obtained by backscattered electrons (BSE) with an accelerating voltage of $20 \mathrm{kV}$ and a beam current of $80 \mu \mathrm{A}$. The BSE signal is better than the secondary-electron signal for detecting mineral particulate, because of its higher atomic number contrast (Paoletti et al., 2002). The dust holder has directly been introduced in the microscope sample chamber without any further preparation. Counting and size distribution of the particles has been obtained from SEM pictures by combining the data obtained with different magnifications. Particles with diameter larger than $5 \mu \mathrm{m}$, have ben analyzed by using the $500 \times$ magnification, those with diameter in the range $1-5 \mu \mathrm{m}$ by the $1000 \times$ magnification, and those with diameter smaller than $1 \mu \mathrm{m}$ by the $3500 \times$ magnification. The Feret diameter that is defined as the average caliper distance of 36 measurements around the particle center employing a $5^{\circ}$ angle of rotation, has been used to determine particle size (Podczeck et al., 1999). The particle shape has been inferred by means of the roundness factor defined by the relation $R=\frac{P^{2}}{4 \pi A}$, where the object's area $\mathrm{A}$ is defined by the number of pixels having intensity values within a selected range and the perimeter $P$ is given by the outline length of each particle. Smooth and round objects have then a roundness factor close to unity, whereas rough or elongated objects have roundness factors larger than one (Nazar et al., 1996). More than 800 particles have been analyzed in every dust sample to make a statistical analysis. An X-ray spectrum has been collected for 200 s for every SEM image, and an X-ray dotted map has been acquired for one hour for every chemical element recognized by the $\mathrm{X}$-ray spectrum. X-ray spectra allow calculating the net Xray peak-area of each element, in order to obtain a first semi quantitative information about the chemical composition of the sample. The X-ray dotted maps have instead been acquired to determine the spatial distribution of selected elements on the investigated area. Indeed, the white dots in every dotted element map, show the sites where the element concentration is high. The dots get gray as the element concentration reduces and the element is absent in the black map areas (Goldstein and Yakowitz, 1975).

\section{Dust event characterization}

The dust samples have been collected under the so-called "dust alerts" issued by the Atmospheric Modeling Weather Forecasting Group of the Athens's University, Greece (http: //forecast.uoa.gr/forecastnew.html). In particular, the results on the characterization of dust samples collected during four strong Sahara dust outbreaks occurred from April to June 2002, are presented in this paper.

The first dust samples have been collected on 12 April, during the strong dust outbreak occurred over the Mediterranean Sea from 8 April to 14 April, in accordance to backtrajectories and SeaWiFS images. The four-day analytical backtrajectories of 12 April at 13:00 UT are shown on Fig. 2a. The atmospheric backward trajectories have been calculated on a 3-dimensional grid with a time resolution of $6 \mathrm{~h}$, by the German Weather Service from the wind fields of the European numerical weather prediction model (Kottmeier and Fay, 1998). It is believed that this calculation method leads to lower uncertainties in comparison to those of other methods, e.g. isentropic calculation. The accuracy of the calculated trajectories depends on the synoptic conditions. The higher the wind-speed the lower is the uncertainty of the trajectories. Usually the deviation between the calculated and the actual track of an air parcel is about $10 \%$ to $20 \%$ of the trajectory length for the trajectories used in this study 
(Stohl, 1998). The data are provided for six distinct arrival height levels $(975,850,700,500,300$, and $200 \mathrm{hPa})$ and for two arrival times (13:00 UT and 19:00 UT) on a day-by-day basis.

One observes from Fig. 2a that south Algeria and Niger (Source 2) are the source regions of the 850 and $500 \mathrm{hPa}$ arrival-height backtrajectory, respectively whereas the backtrajectory characterized by the arrival height-level of $700 \mathrm{hPa}$ has the origin in Chad (Source 2), following d'Almeida (1986). The height-level versus time of each backtrajectory is shown on the right side of Fig. 2a, and it can be observed that the initial height-level $(-96 \mathrm{~h})$ of the 850,700 , and $500 \mathrm{hPa}$ backtrajectory, respectively is close to $850 \mathrm{hPa}$. A larger dependence of the monitored aerosol properties on source regions is expected when the backtrajectories are characterized by height-levels closer to ground and larger residence times on the source area. A clear view of suspended Sahara dust particles over the Mediterranean Sea on 11 April is given by the true color image (Fig. 3) provided by the Sea-viewing Wide Field-of-view Sensor (SeaWiFS) that is carried by the SeaStar spacecraft on the NASA Earth Observing System AM platform (Hooker et al., 1992). The TOMS absorbing aerosol index also represents an ideal tool to monitor intensity and pathway of desert dust on a 24-hours basis (Herman et al., 1997), as it has been previously mentioned. The TOMS data of 12 April provide AAI values between 1.2-2.2 over the south-eastern cost of Italy (http://toms.gsfc.nasa.gov/aerosols/aerosols.html).

Dust samples have also been collected on 13 May, the last day of the dust outbreak over the Mediterranean Sea started on 7 May. Figure 2b shows the analytical back trajectories of 13 May at 13:00 UT and one observes that south Algeria (Source 2, from d'Almeida, 1986) and north Lybia (Source B, from Prospero et al., 2002) are the source regions of the 850 and $700 \mathrm{hPa}$ arrival-height backtrajectory, respectively. The TOMS AAI varies on 13 May between 1.2-1.7 over the southeast cost of Italy.

A strong dust event has also occurred on 24-26 May and dust samples have been collected on 24 May. Figure 2c shows the back trajectories of 24 May at 13:00 UT and reveals that the 700 and $500 \mathrm{hPa}$ arrival-height backtrajectories have the origin on Lybia and south Mauritania, respectively. AAI values ranging from 0.7 to 1.7 are provided on 24 May by TOMS over the south-east Mediterranean Sea. The presence of dust over the southeast Mediterranean Sea is also revealed by the true color SeaWiFS image of 24 May.

Finally, some dust samples have been collected on 7 June. This last dust event has lasted from 5-10 June. The backtrajectories of 7 June at 13:00 UT are shown on Fig. 2d, and we observe that the $850 \mathrm{hPa}$-backtrajectory has the origin on the Mediterranean Sea but, it crosses the Eastern Lybian desert (Source B) at quite low height levels before arriving to Lecce. Morocco (Source 1) is the origin region of the $700 \mathrm{hPa}$-backtrajectory and it is worth noting that this last backtrajectory crosses the Mediterranean Sea at quite low
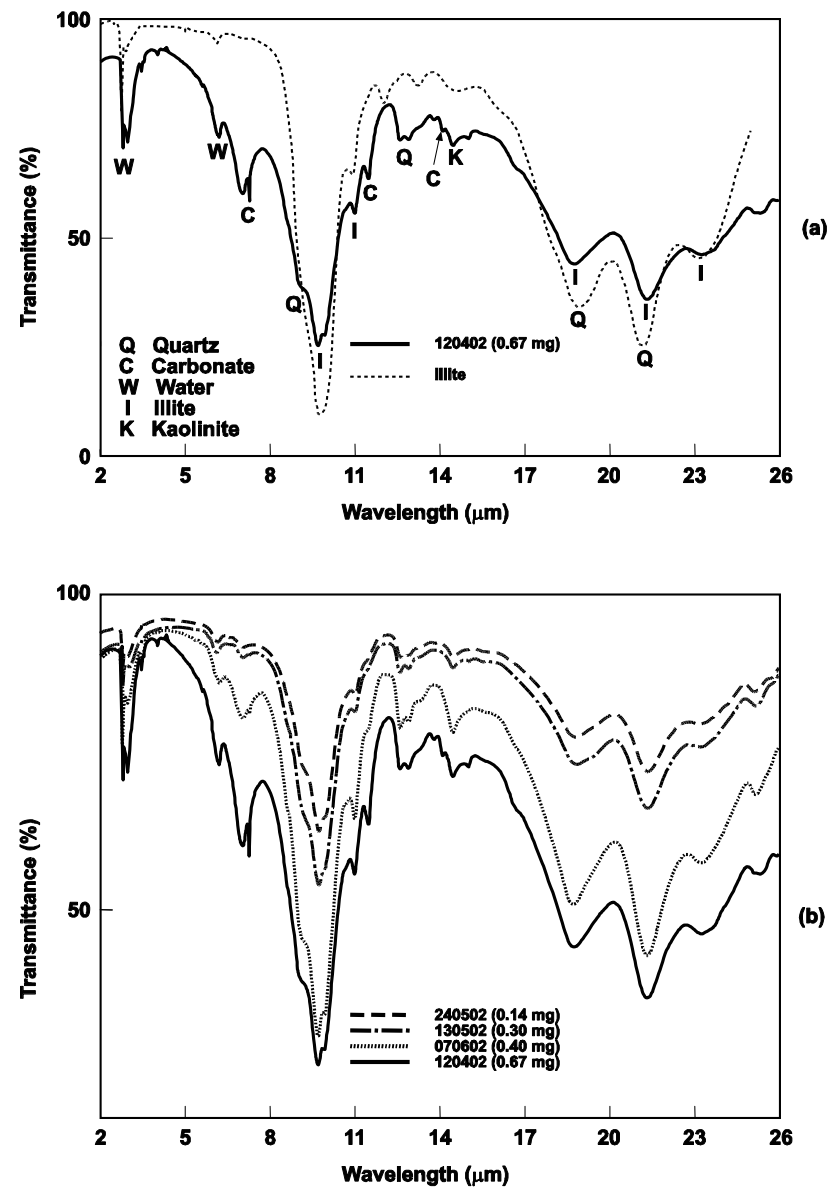

Fig. 4. Infrared potassium bromide transmission spectra of dust samples that have been collected at Lecce: (a) during the dust event of 12 April (solid line), the dotted line is the transmission spectrum of illite taken from Salisbury et al. (1991); (b) during all dust events of 24 May, 13 May, 7 June and 12 April. The value of the dust mass embedded in the potassium bromide is also reported in brackets.

height levels before getting to Lecce. The SeaWiFS true color image of 7 June clearly shows the presence of dust over the Mediterranean Sea where AAI values ranging from 0.7 to 2.2 are provided by TOMS.

The above reported data clearly show that the dust samples have been collected during strong dust outbreaks occurred over the south-east Mediterranean Sea and that dust particles from Source 1, 2, and 3 accordingly to d'Almeida (1986), and from the south of the northern Atlas Mountains (Source A), and from the Eastern Lybian Desert (Source B) accordingly to Prospero et al. (2002), have mainly been advected to Lecce. 

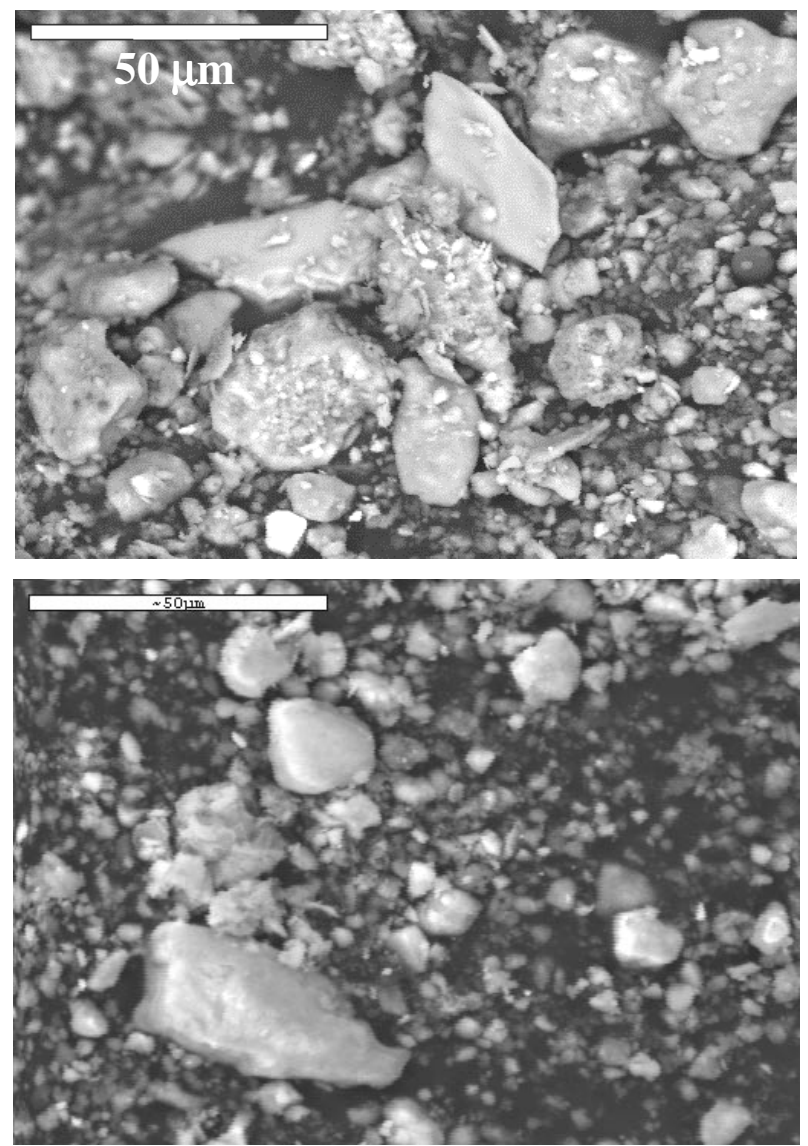

(a)

Fig. 5. Illustrative backscattered electron (BSE) image of the particles collected during the dust storm of (a) 12 April and (b) 7 June.

\section{Results and discussion}

\subsection{Infrared transmission spectroscopy measurements}

Qualitative information on the major chemical constituents of the dust samples have been obtained by infrared transmission spectroscopy measurements. The results are shown in Figs. 4a and 4b. The solid line in Fig. 4a represents a typical transmittance spectrum of the samples collected on 12 April. Several dust samples have been analyzed and it has been found that the transmittance spectrum was not dependent on the sample. A comparison of this spectrum with an infrared spectral library of minerals (Salisbury et al., 1991), allows us to recognize that the collected dust contains a significant amount of illite $\left(\mathrm{K}, \mathrm{H}_{3} \mathrm{O}\right)(\mathrm{Al}, \mathrm{Mg}, \mathrm{Fe})_{2}(\mathrm{Si}, \mathrm{Al})_{4} \mathrm{O}_{10}\left[(\mathrm{OH})_{2}, \mathrm{H}_{2} \mathrm{O}\right]$, a mineral classified as a phyllosilicate of the mica group with absorption bands centered around $9.7 \mu \mathrm{m}, 11.0 \mu \mathrm{m}$, $18.9 \mu \mathrm{m}, 21.3 \mu \mathrm{m}$ and $23.5 \mu \mathrm{m}$. The transmittance spectrum of illite taken from Salisbury et al. (1991) is also shown in Fig. 4a (dotted line) for comparison. The contribution of some carbonate (C) bands at $7 \mu \mathrm{m}, 11.5 \mu \mathrm{m}$ and $14 \mu \mathrm{m}$, and quartz (Q) bands at $9.3 \mu \mathrm{m}, 12.5 \mu \mathrm{m}, 18.9 \mu \mathrm{m}$ and 21.3, can

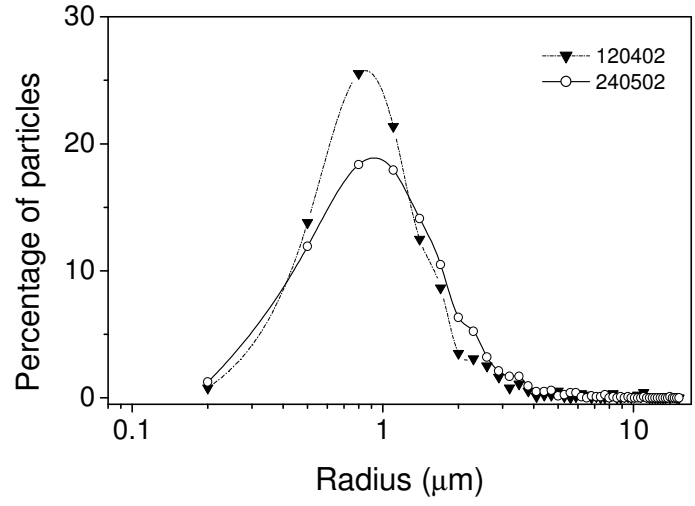

(a)

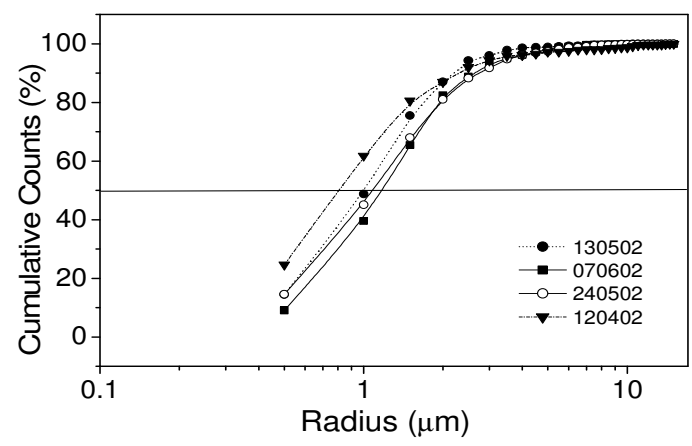

(b)

(b) Fig. 6. (a) Tipical size distribution of aerosol particles collected during the dust storm of 12 April and 24 May. 913 and 1182 particles have been analyzed on the dust sample of 12 April and 24 May, respectively. (b) Cumulative grain-size curves of the samples collected in the different dust storm events.

also be observed in the transmittance spectrum of Fig. 4a (solid line). The absorption band at $14.4 \mu \mathrm{m}$ can be ascribed to the presence of kaolinite (K). The strongest absorption bands of kaolinite at 9.3, 18.5, 21.2 and $23.2 \mu \mathrm{m}$ superimpose to the illite ones even if they have a rather different spectral structure. The strong features clearly visible in Fig. 4a (solid line) around $2.9 \mu \mathrm{m}$ and $6.1 \mu \mathrm{m}$, can certainly be ascribed to the $\mathrm{O}-\mathrm{H}$ stretching vibrations and to the $\mathrm{H}-\mathrm{O}-\mathrm{H}$ bending vibrations of water $(\mathrm{W})$, respectively. Typical transmittance spectra of the samples collected on 13 and 24 May, and on 7 June are shown on Fig. $4 \mathrm{~b}$ besides the spectrum of 12 April. The value of the dust mass embedded in the potassium bromide powder is also reported in brackets for every sample. The uncertainties on dust mass values are lower than $15 \%$. The transmittance spectra of Fig. $4 \mathrm{~b}$ are characterized by very similar spectral features and lead to consider that all dust samples have similar chemical composition and therefore contain a significant amount of illite. These results are in satisfactory accordance with those obtained by Avila et al. (1997) by analyzing 11-year records of African dust rains in the Montseny mountain (northestern Spain). They have found by analyzing 


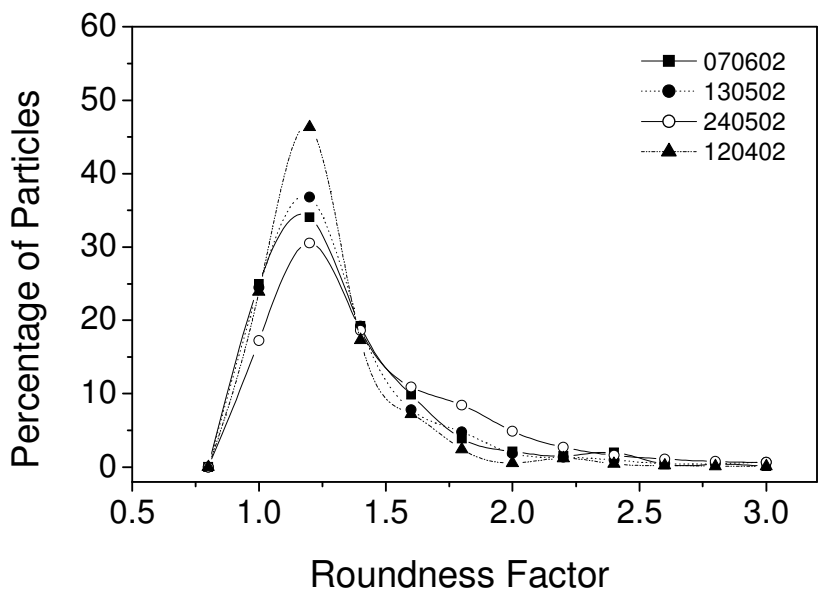

Fig. 7. Roundness factor distribution of the particles collected during the dust storm events. The total number of analyzed particles is: 913 on the 120402 sample; 1025 on the 130502 sample; 1182 on the 240502 sample; 802 on the 070602 sample

isentropic back trajectories, that Western Sahara, Moroccan Atlas, and Central Algeria were the main source regions of the monitored dust events, in accordance with Figs. 1 and 2 of this paper. Moreover, they have observed that illite was the most abundant mineral identified in all dust samples by $\mathrm{X}$ ray diffraction and that the illite concentration was $41 \%$ when the source region was western Sahara, and $34.5 \%$ for the air masses coming from central Algeria. They have also shown that the differences in mineralogy between source regions were significant for the lower content mineral: smectite $\left(\mathrm{K}, \mathrm{H}_{3} \mathrm{O}\right)(\mathrm{Al}, \mathrm{Mg}, \mathrm{Fe})_{2}(\mathrm{Si}, \mathrm{Al})_{4} \mathrm{O}_{10}\left[(\mathrm{OH})_{2}, \mathrm{H}_{2} \mathrm{O}\right]$, kaolinite $\mathrm{Al}_{2} \mathrm{Si}_{2} \mathrm{O}_{5}(\mathrm{OH})_{4}$, quartz $\mathrm{SiO}_{2}$, and dolomite $\mathrm{CaMg}\left(\mathrm{CO}_{3}\right)_{2}$. Smectite and kaolinite content was highest in the Algerian events, while quartz and dolomite content was lowest. Events from the Moroccan Atlas had the lowest smectite and kaolinite. Guerzoni et al. (1997) by considering the results on the mineralogical composition of Sahara dust samples collected at different Mediterranean sites along several years (1984-1992), have also shown that the Sahara dust samples have generally relatively high concentrations of illite, in accordance with our and Avila et al. (1997) experimental results. The studies of Molinaroli (1996) on the mineralogical characterization of Sahara dust with a view to its final destination in the Mediterranean sediments, have also revealed that illite was always more abundant in dust than in sediments. Illite, quartz, and kaolinite were also the main components found by Prodi and Fea (1979) by performing Xray diffraction analysis on dust samples collected in northern Italy on 18 and 19 May 1977. On the contrary, more kaolinite than illite has been found by Chester et al. (1977) in the desert-derived dusts collected in the eastern Mediterranean Sea. Finally, the investigations of Ganor (1991) and of Ganor and Foner (1995) on the mineral composition of eolian dust sampled in Israel and originated from different geographi-

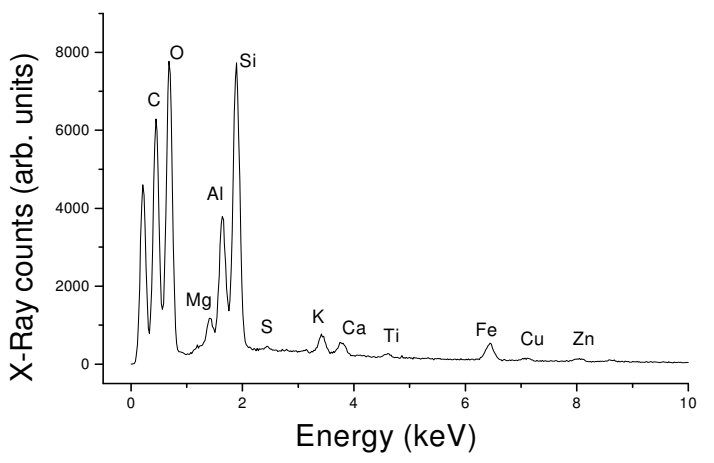

(a)

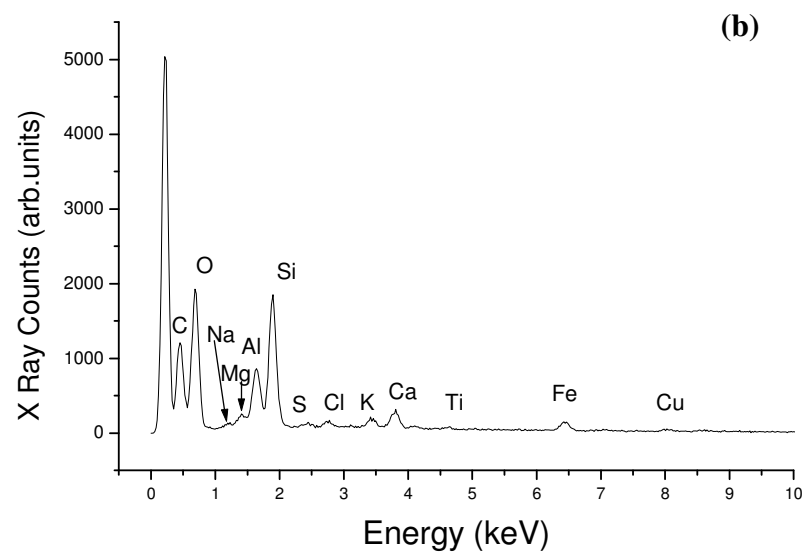

Fig. 8. Typical EDX elemental analysis of the dust samples of (a) 120402 and (b) 070602.

cal sources have revealed that the dust storms originated in Chad and Lybia were characterized by a high content of illite (87\%), whereas the ones originated in Libyan and Egypt were characterized by high concentrations of smectite $(55 \%)$ and kaolinite (30\%). Sokolik and Toon (1999) have also reported that the dust originating from Ahaggar Massif (Source 2, Fig. 1) is characterized by a high abundance of illite, while the dust from the Tibesti Mountains (Egyptian, Libyan, and Negev deserts) has moderate concentrations of illite, kaolinite and montmorillonite.

\subsection{Measurements of the particle size and roundness factor distribution}

Scanning electron microscopy and X-ray energy dispersive measurements have been performed for the dust particle-size and shape analysis and to get more data on the elemental composition of the dust samples. The back scattered electron (BSE) image of the dust particles collected during the dust storm of 12 April and 7 June are shown in Figs. 5a and $5 \mathrm{~b}$, respectively. The particle-size analyses of our samples have revealed the presence of silty clays, particle with diameter up to $4 \mu \mathrm{m}$, and clayey silts, particles with diameter larger than $4 \mu \mathrm{m}$ (Molinaroli et al., 1993). Indeed, dust particles with diameter ranging from 0.3 to $30 \mu \mathrm{m}$ and maximum 

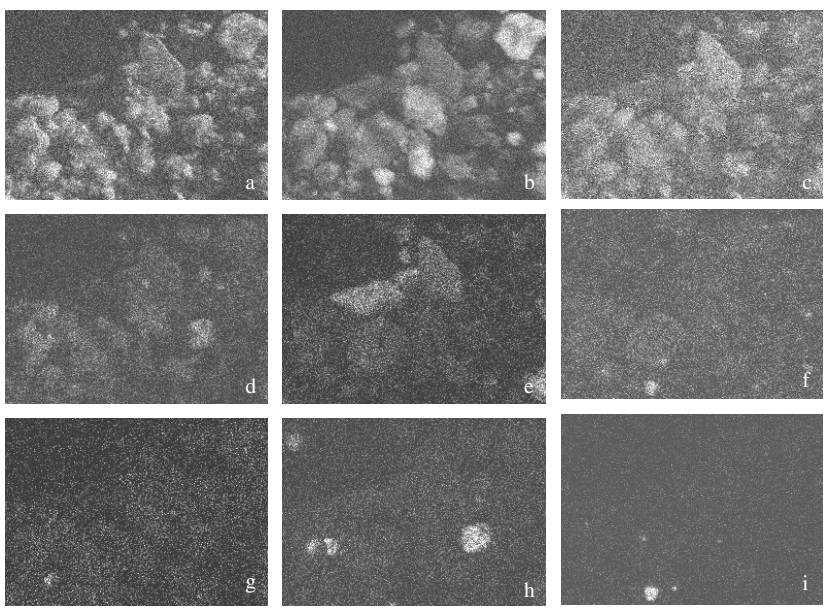

Fig. 9. Elemental X-ray dotted maps obtained from the BSE image of Fig. 5 a, showing the particles containing: (a) O, (b) Si, (c) Al, (d) $\mathrm{Mg}$, (e) K, (f) $\mathrm{Fe}$, (g) S, (h) Ca and (i) Ti.

concentration at about $2 \mu \mathrm{m}$ have been measured in all samples. Figure 6a shows as an example the particle distribution of dust samples collected on 12 April (sample 120402) and 24 May (sample 240502), respectively. 913 and 1182 particles have been analyzed on the dust sample of 12 April and 24 May, respectively. Measurements of the atmospheric aerosol size distributions are essential in identifying the various processes involved in the formation and evolution of atmospheric aerosols (Raes et al., 2000). Figure 6b shows the cumulative grain-size curves as function of the particle radius, of typical samples collected during the investigated dust storms. One observes a similar size distribution with median-diameter values between 1.7-2.4 $\mu \mathrm{m}$ in all samples. Particles with minimum and maximum observed size of 0.08 and $16 \mu \mathrm{m}$, respectively have been obtained by Prodi and Fea (1979) from muddy rain samples collected at Sestola and Bologna on 18 and 19 May 1977. Both collection sites are about $1600 \mathrm{~km}$ away from the Africa coast. On the contrary, the particle size distribution of two Sahara rain samples collected at a Sardinia station in March 1992 and October 1993, showed modes at $8 \mu \mathrm{m}$ and $25-50 \mu \mathrm{m}$ in diameter for the first and a single mode between 20 and $40 \mathrm{~m}$ for the second, with a tail towards the finest particles (Guerzoni et al., 1997). The Sardinia collection site was about $400 \mathrm{~km}$ away from the Africa coast. It appears from the results presented above that the maximum particle diameter reduces as the distance from the dust source area increases. Aerosols are removed from the atmosphere by dry and wet processes and it is well known that large particles (diameter $>1 \mu \mathrm{m}$ ) settle gravitationally: a process which becomes more efficient as the particles size increases (Raes et al., 2000). Hence, the removal of large diameter particles as a consequence of gravitational settling can be responsible of the differences in size distribution of the Sahara rain samples collected at Bologna and Sestola, Lecce, and Sardinia. However, it is worth mentioning that
Table 1. Element/Si ratios of the collected dust samples.

\begin{tabular}{ccccc}
\hline Element & 240502 & 120402 & 130502 & 070602 \\
\hline $\mathrm{O} / \mathrm{Si}$ & 0.76 & 0.79 & 0.87 & 0.70 \\
$\mathrm{Mg} / \mathrm{Si}$ & 0.16 & 0.16 & 0.16 & 0.13 \\
$\mathrm{Al} / \mathrm{Si}$ & 0.50 & 0.48 & 0.45 & 0.41 \\
$\mathrm{Si} / \mathrm{Si}$ & 1 & 1 & 1 & 1 \\
$\mathrm{~S} / \mathrm{Si}$ & 0.09 & 0.08 & 0.13 & 0.09 \\
$\mathrm{~K} / \mathrm{Si}$ & 0.15 & 0.14 & 0.15 & 0.11 \\
$\mathrm{Ca} / \mathrm{Si}$ & 0.10 & 0.11 & 0.12 & 0.15 \\
$\mathrm{Ti} / \mathrm{Si}$ & 0.07 & 0.06 & 0.07 & 0.06 \\
$\mathrm{Fe} / \mathrm{Si}$ & 0.11 & 0.11 & 0.10 & 0.09 \\
$\mathrm{Cu} / \mathrm{Si}$ & 0.04 & 0.04 & 0.05 & 0.04 \\
$\mathrm{Zn} / \mathrm{Si}$ & 0.03 & 0.03 & 0.04 & 0.03 \\
\hline
\end{tabular}

it has been shown by Guerzoni et al. (1997) that the particle size distribution in the Sahara outbreaks exhibits no clear relationship between median, or modal particle-size and transport distance. Grain size fractionation is not a clear function of aerosol sedimentation velocity, and factors other than gravitation and turbulence may play an important role.

The BSE images of Figs. 5a and 5b show that the particles are generally sharp-edged and irregular in shape. It is well known that dust-like aerosols cannot be assumed to be spherical (Barnaba and Gobbi, 2001) and that as a consequence, their optical properties can significantly differ from those calculated by means of the Mie theory (Mishchenko et al., 1997). It is therefore of peculiar importance to evaluate the dust particle roundness to better infer their light scattering properties. The roundness factor $R$ (Nazar et al., 1996) has been used for the first time in this paper to evaluate the sharpness of edges and corners of the dust particles and the results are shown on Fig. 7. One observes that all samples show an unimodal roundness factor distribution with the peak at $R \approx 1.25$ and with the $R$ values ranging from about 0.8 to 2.5. Elliptical and spherical particles are characterized by $R$ values ranging from 1 to 1.25 , whereas $R$ varies from 1.4 to 2.5 for triangle particles, accordingly to Podczeck et al. (1999). No clear relation has been found between average $R$ value and grain size.

\subsection{X-ray energy dispersive measurements}

Typical X-ray spectra of the dust samples collected (a) on 12 April and (b) on 7 June are shown in Fig. 8. One observes that the particles contain elements such as $\mathrm{Al}, \mathrm{Si}, \mathrm{Ca}$, $\mathrm{Fe} \mathrm{K}, \mathrm{Mg}$, Ti and also $\mathrm{Cu}$ and $\mathrm{Zn}$ traces. $\mathrm{Na}$ and $\mathrm{Cl}$ traces have also been found in the 070602 sample (Fig. 8b). Even though, $\mathrm{C}$ has been detected, it has not been considered in the data analysis because it represents the major component of the adhesive layer, on which dust has been deposited for SEM analyses. X-ray spectra similar to that of Fig. 8a have been found for all samples collected during the monitored 

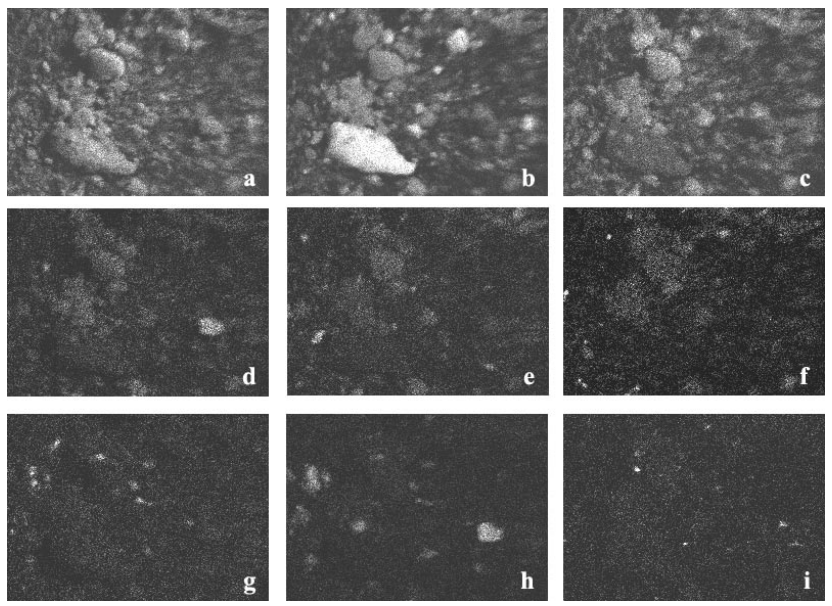

Fig. 10. Elemental $X$-ray dotted maps obtained from the BSE image of Fig. 5b, showing the particles containing: (a) O, (b) Si, (c) Al, (d) $\mathrm{Mg}$, (e) K, (f) $\mathrm{Fe}$, (g) S, (h) Ca and (i) Ti.

dust events. A semi quantitative analysis of the relative abundance of the different elements with respect to Si has been carried out in all samples (Levin et al., 1979). Table 1 summarizes the X-ray count ratios of the different elements with respect to Si that have been obtained with $200 \mathrm{~s}$ counting time. The dust event date (ddmmyy) is used to characterize every sample. One observes from Table 1 that the $\mathrm{Al} / \mathrm{Si}$ ratio reaches quite high values ranging from 0.41 to 0.5 . The $\mathrm{Al} / \mathrm{Si}$ ratio is considered a good discriminator between desert- and anthropogenic-dominated samples, with high values in the former group and low ones in the latter (Molinaroli et al., 1993). Indeed, Al/Si ratios higher than 0.3 are generally considered indicative of the desert origin of the particles (Guerzoni et al., 1997). It is worth noting that rather low content of $\mathrm{S}, \mathrm{Cu}$ and $\mathrm{Zn}$ has been observed in all samples and further X-Ray mapping was not able to dot any particle containing the last two element. One also observes from Table 1 that the Element/Si ratios have similar distribution in all analyzed dust samples in accordance with infrared transmission spectroscopy measurements that have lead to consider that all samples have similar chemical composition. The results of Table 1 are also in good accordance with the ones reported by Molinaroli et al. (1993) for the desert-dominated sample.

It is worth observing from Table 1 that the samples with larger $\mathrm{K} / \mathrm{Si}$ ratio have larger $\mathrm{Fe} / \mathrm{Si}$ and $\mathrm{Mg} / \mathrm{Si}$ ratios, whereas the samples with larger $\mathrm{Ca} / \mathrm{Si}$ have lower $\mathrm{K} / \mathrm{Si}, \mathrm{Fe} / \mathrm{Si}$ and $\mathrm{Mg} / \mathrm{Si}$ ratio. To better understand the observed trends of some element/Si ratios, and to evaluate whether the composition of the dust sampled at Lecce differs according to the origin, we have computed for all samples the $\mathrm{Ca} / \mathrm{Al}$, $\mathrm{Fe} / \mathrm{Ca}, \mathrm{K} / \mathrm{Ca}$, and $\mathrm{Si} / \mathrm{Al}$ ratios, since the differences in mineralogy between source regions can be significant for smectite $\left(\mathrm{K}, \mathrm{H}_{3} \mathrm{O}\right)(\mathrm{Al}, \mathrm{Mg}, \mathrm{Fe})_{2}(\mathrm{Si}, \mathrm{Al})_{4} \mathrm{O}_{10}\left[(\mathrm{OH})_{2}, \mathrm{H}_{2} \mathrm{O}\right]$, kaolinite Al2Si2O5(OH)4, quartz $\mathrm{SiO}_{2}$, and dolomite $\mathrm{CaMg}\left(\mathrm{CO}_{3}\right)_{2}$, according to Avila et al. (1997). The results summarized in
Table 2. Ratios between two elements of the collected dust samples.

\begin{tabular}{ccccc}
\hline Element & 240502 & 120402 & 130502 & 070602 \\
\hline $\mathrm{Ca} / \mathrm{Al}$ & 0.20 & 0.23 & 0.27 & 0.37 \\
$\mathrm{Fe} / \mathrm{Ca}$ & 1.10 & 1.00 & 0.83 & 0.60 \\
$\mathrm{~K} / \mathrm{Ca}$ & 1.50 & 1.27 & 1.25 & 0.73 \\
$\mathrm{Si} / \mathrm{Al}$ & 2.00 & 2.08 & 2.22 & 2.44 \\
\hline
\end{tabular}

Table 2 show that larger $\mathrm{Si} / \mathrm{Al}$ and $\mathrm{Ca} / \mathrm{Al}$ ratios have been found for the dust storms of 13 May and 7 June. Larger Si/Al and $\mathrm{Ca} / \mathrm{Al}$ ratios can be ascribed to dust samples with a larger content of quartz, calcite, and dolomite according to Avila et al. (1997). To this end, it is also worth observing that Avila et al. (1997) have found the largest percentage of dolomite, calcite, and quartz in dust coming from Moroccan Atlas. The backtrajectories shown in Fig. 2 reveal that dust coming from Morocco has been collected at Lecce only on 7 June, and Table 2 shows that the largest $\mathrm{Si} / \mathrm{Al}$ and $\mathrm{Ca} / \mathrm{Al}$ ratios have been found for the dust collected on 7 June, in accordance to Avila et al. (1997) results. Table 2 also shows that lower Si/Al ratios and larger $\mathrm{Fe} / \mathrm{Ca}$ and $\mathrm{K} / \mathrm{Ca}$ ratios have been found in dust samples collected on 24 May and 12 April. These last ratio values can be ascribed to dust samples with a larger content of illite, smectite, and kaolinite, which are the major components of dust coming from central Algeria, according to Avila et al. (1997). The studies of Ganor (1991) and of Ganor and Foner (1995) on the mineral composition of eolian dust sampled in Israel have also revealed that the dust storms originated in Chad and Lybia were characterized by a high content of illite, kaolinite, and smectite. To this end, it is worth observing from Fig. 2 that Chad, Niger, Algeria and Libya are the main source regions of the dust events of 12 April and May 24. In particular, it is worth noting that on 24 May, the $700 \mathrm{hPa}$ backtrajectory crosses Libya at height levels of about $950 \mathrm{hPa}$, before arriving to Lecce. In conclusion, Tables 1 and 2, and Fig. 2 shows that dust samples with larger $\mathrm{Ca} / \mathrm{Al}$ and $\mathrm{Si} / \mathrm{Al}$ ratios and lower $\mathrm{Fe} / \mathrm{Ca}$ and $\mathrm{K} / \mathrm{Ca}$ ratios, and therefore with a larger content of quartz, calcite, and dolomite (Avila et al., 1997), have been collected along dust events with a source region in northwestern Sahara. On the contrary, the samples collected along dust events with the origin mainly in Chad, Niger, Algeria and Lybia were characterized by larger $\mathrm{Fe} / \mathrm{Ca}$ and $\mathrm{K} / \mathrm{Ca}$ ratios for the larger content of smectite and kaolinite (Avila et al., 1997). A similar trend has also been observed by Chiapello et al. (1997) at Sal Island on the basis of 3 years of daily measurements of mineral dust concentrations, by Bergametti et al. (1989b) in the Canary Islands, and by Bergametti et al. (1989a) in Corsica. However, different $\mathrm{Ca} / \mathrm{Al}, \mathrm{Fe} / \mathrm{Ca}, \mathrm{K} / \mathrm{Ca}$, and $\mathrm{Si} / \mathrm{Al}$ values have been found at the different observation sites. In fact, the ratio between two selected elements can be affected by gravitational settling and/or other processes such as turbulence (Guerzoni 


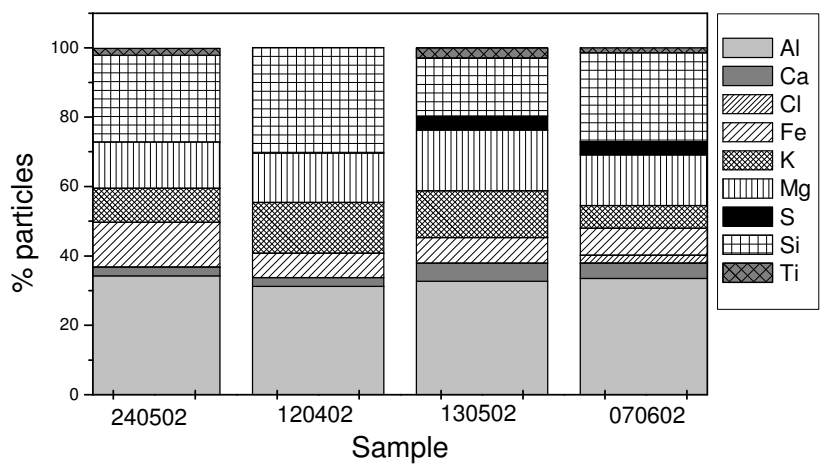

Fig. 11. Elemental percentage in the investigated dust samples.

et al., 1997). A clear variation of the $\mathrm{Al} / \mathrm{Si}$ ratios with particle size has been found by Coude-Gaussen et al. (1987) at Fuerteventura Island by collecting African dust with a cascade impactor.

\subsection{Results from the BES dotted images}

Selected elements (O, Si, Al, Mg, K, Fe, S, Ca, and Ti) have finally been dotted on the BSE image of each analyzed dust sample. This method allows getting the spatial distribution of different elements in the sample and in single particles and can allow inferring the chemical composition of each particle, and to know about its morphological features (Feret diameter and roundness factor). Figures $9 \mathrm{a}-9 \mathrm{i}$ and $10 \mathrm{a}-10 \mathrm{i}$ show as an example the dotted images obtained from the BSE image of Figs. 5a and 5b, respectively. The white dots in Figs. 9a-9i and Figs. 10a-10i show the sites on the BSE image where (a) $\mathrm{O}$, (b) $\mathrm{Si}$, (c) $\mathrm{Al}$, (d) $\mathrm{Mg}$, (e) $\mathrm{K}$, (f) $\mathrm{Fe}$, (g) $\mathrm{S}$, (h) $\mathrm{Ca}$, and (i) $\mathrm{Ti}$ has been detected, respectively. Oxigen has obviously been found in all particles. One also observes from Figs. 9 and 10 that some elements are always present together. $\mathrm{Al}, \mathrm{Mg}$ and $\mathrm{K}$ have almost always been found in particles containing $\mathrm{Si}$. This result further more allows recognizing that the collected dust contain illite and/or smectite. $\mathrm{Fe}$, when it is present, has often been found together with at least one of the main elements ( $\mathrm{Al}, \mathrm{Mg}, \mathrm{K}$ and $\mathrm{Si}$ ) and it has been found combined with $\mathrm{O}$ only in a very little percentage of particles, varying from $0.6 \%$ to $2.3 \%$ in the different samples. In fact, only a few studies reported hematite (a major source of light absorption) in Sahara dust samples along with the most observed minerals as illite, quartz, smectite, kaolite, calcite and dolomite (Sokolik and Toon, 1999; Guerzoni et al., 1997). K that has always been observed with $\mathrm{Si}$, has not been found with $\mathrm{Ca}$. On the contrary, $\mathrm{S}$ has always been found in particles containing $\mathrm{Ca}$. This last result suggests the presence of gypsum on the collected dust. Finally, Fig. 9 reveals that the particle on the right side of Fig. 9h that is characterized by a high content of $\mathrm{Ca}$, is also made of $\mathrm{Mg}$ (Fig. 9d) and O (Fig. 9a), and hence it can be a particle of dolomite $\left(\mathrm{CaMg}\left(\mathrm{CO}_{3}\right)_{2}\right)$. Figure 10 lead also to con-
Table 3. Percentage of particles containing both $\mathrm{Ca}$ and $\mathrm{Mg}$ in the investigated dust samples.

\begin{tabular}{cccc}
\hline 240502 & 120402 & 130502 & 070602 \\
\hline $1.3 \%$ & $0.7 \%$ & $1.4 \%$ & $2.3 \%$ \\
\hline
\end{tabular}

sider that the particle on the right side of Fig. 10h is made of dolomite. The dotted BSE images have then been used to find out the percentage of particles containing both $\mathrm{Ca}$ and $\mathrm{Mg}$ in the investigated dust samples. The results are reported in Table 3 and show that the dust sample of 7 June has the largest percentage (2.3\%) of particles containing $\mathrm{Ca}$ and $\mathrm{Mg}$. The main source regions of this dust event (Fig. 2d) are Morocco (700 hPa-arrival height backtrajectory) and north Libya $(850 \mathrm{hPa})$. On the contrary, the percentage of particles containing $\mathrm{Ca}$ and $\mathrm{Mg}$ is lowest $(0.7 \%)$ for the dust sample of 12 April whose backtrajectories (Fig. 2a) have the origin in Chad $(700 \mathrm{hPa})$, Niger $(500 \mathrm{hPa})$ and Algeria $(850 \mathrm{hPa})$. These last results are in good accordance with those of the previous paragraph and show further more that the differences in mineralogy between source regions are significant for the lower content mineral: smectite, kaolinite, quartz, and dolomite (Avila et al., 1997).

The dotted maps have then been used to find out the particle percentage containing a given element for every element of the dust samples. Results are shown in Fig. 11 and it is worth observing that the percentage of particles containing a given element varies from sample to sample, even though the percentage of particles containing $\mathrm{Al}, \mathrm{Si}, \mathrm{K}, \mathrm{Mg}$, and $\mathrm{Fe}$ is rather similar among the samples. The presence of particles containing $\mathrm{Cl}$ revealed by Fig. 11 for the dust sample of 7 June, besides the presence of $\mathrm{Na}$ and $\mathrm{Cl}$ revealed by the $\mathrm{X}$ ray spectrum of Fig. 8b, leads to infer the presence of $\mathrm{NaCl}$ particles from the sea in the 070602 sample. This conclusion is also supported by Fig. $2 \mathrm{~d}$ showing that most of the $700 \mathrm{hPa}$ back trajectory pathway is performed on the Mediterranean Sea at low height levels.

It is interesting to note from Fig. 11 that a decreasing in the particle percentage containing $\mathrm{Ca}$ is accompanied by the absence of particles containing $\mathrm{S}$ particles. In fact, particles containing $S$ have not been observed in the 240502 and 120402 sample: both samples are characterized by the lowest percentage of Ca-particles. This result leads to consider once again that the presence of $\mathrm{S}$ revealed in the 070602 and 130502 samples, is probably associated with $\mathrm{Ca}$.

Finally, the size distribution of particles containing a given element has been determined for every element of the dust samples and it has been found that every element sizeparticle distribution follows the corresponding overall particle distribution. Figure 12 shows as example the size distribution of Al-containing particles in the 120402 and 240502 sample. Al has been chosen as one the most representative 
elements of Saharan dust. It can be observed from Fig. 12 that the Al-particle distribution follows the overall particle distribution (Fig. 6a) with a peak concentration at about $1.5 \mu \mathrm{m}$ in both samples.

\section{Summary and conclusion}

Water-insoluble components of Saharan dust samples from rainfall residues have for the first time been collected at a rural site, in the south-eastern corner of Italy during Saharan dust storm events, and have been characterized by SEM, Xray microanalysis, and infrared spectroscopy measurements. Four-day analytical back trajectories, SeaWiFS true color images and absorbing aerosol index values provided by TOMS have been used to support the Sahara origin of the investigated dust samples. Detailed information on the elemental composition, size and shape distribution of the dust particles has been provided by the X-ray map single particle analysis. Qualitative results on the major chemical constituents of the dust samples have been obtained by infrared transmission spectroscopy measurements. The different analyses performed on the dust samples have provided results in satisfactory accordance and have demonstrated that the Saharan dust particles of different rainfall events were characterized by similar elemental composition. These results are in good agreement with the fact that the back trajectories of the investigated dust storms (Fig. 2) have the source regions mainly on central and western Sahara. Dust particles with diameter ranging from 0.3 to $30 \mu \mathrm{m}$ and maximum concentration at about $2 \mu \mathrm{m}$ have been observed in all samples (Figs. 6a and 6b). The rain samples collected at Sestola and Bologna (Prodi and Fea, 1979), and in south Sardinia (Guerzoni et al., 1997) were characterized by particle distributions with maximum concentration at about $0.1-0.24 \mu \mathrm{m}$ and $20-40 \mu \mathrm{m}$, respectively. The removal of large diameter particles as a consequence of gravitational settling has been considered responsible of the differences in size distribution of the rain samples collected at Sestola and Bologna, Lecce and Sardinia. The dust particle roundness factor has for the first time been reported in this paper and it has been found that it takes values ranging from about 0.8 to 2.5 with the peak at $R \approx 1.25$ in all samples (Fig. 7). This parameter is of peculiar importance to evaluate the light scattering properties of the dust particles (Mishchenko et al., 1997).

Infrared spectroscopy measurements have revealed that the transmittance spectra were characterized by very similar spectral features in all samples. Strong absorption bands in the 9-11 $\mu \mathrm{m}$ and $18-26 \mu \mathrm{m}$ spectral ranges have been observed in all samples. Let us mention that the strong absorption bands in the $8-12 \mu \mathrm{m}$ atmospheric window leads to an increase of the green-house effect in the thermal infrared. A comparison of the dust transmittance spectra with an infrared spectral library of minerals has also allowed us recognizing that the collected dust contained a significant amount of il-

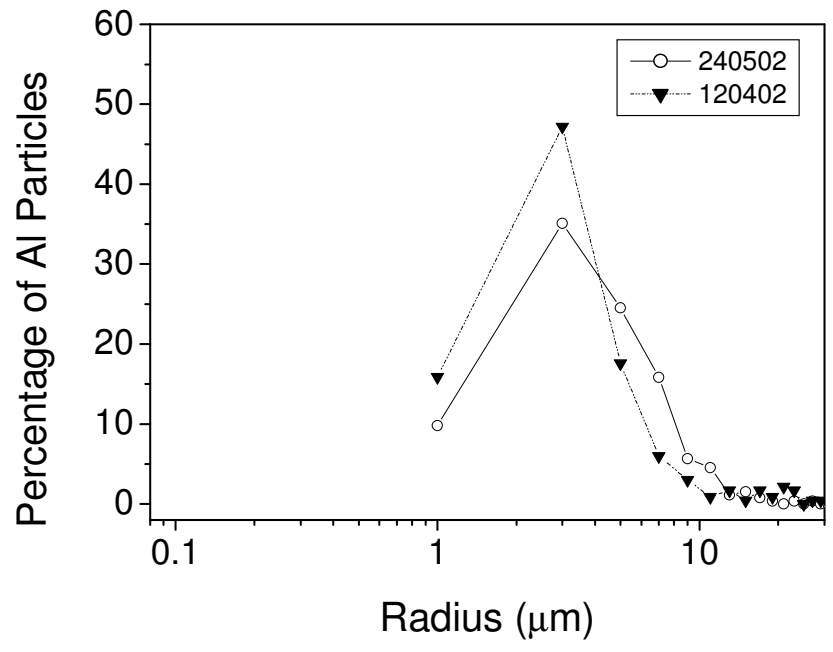

Fig. 12. Size distribution of the particles containing $\mathrm{Al}$ in the 240502, and 120402 samples. 265 and $233 \mathrm{Al}$ particles have been analyzed on the 240502 and on the 120402 sample, respectively.

lite in all samples. This last conclusion supported by the EDX measurements and the dotted BSE image analysis, is in satisfactory accordance with the results reported by Prodi and Fea (1979), Guerzoni et al. (1997), Avila et al. (1997), and Chiapello et al. (1997). Therefore, the results of this paper besides the ones reported in the above mentioned references show that dust particles with a high content of illite are mainly advected over the Mediteranean basin during dust storm events. The EDX measurements have revealed once more that $\mathrm{Al} / \mathrm{Si}$ ratios higher than 0.4 are always indicative of the desert origin of the particles. On the contrary, $\mathrm{Ca} / \mathrm{Al}$, $\mathrm{K} / \mathrm{Ca}, \mathrm{Fe} / \mathrm{Ca}$ and $\mathrm{Si} / \mathrm{Al}$ ratios have allowed us to infer that the smectite and kaolinite amount is higher in the south and central Sahara events, in accordance with literature data. Tables 1, 2, and 3, and Fig. 2 have also revealed that dust samples with larger $\mathrm{Ca} / \mathrm{Al}$ and $\mathrm{Si} / \mathrm{Al}$ ratios and lower $\mathrm{Fe} / \mathrm{Ca}$ and $\mathrm{K} / \mathrm{Ca}$ ratios, and therefore with a larger content of quartz, calcite, and dolomite (Avila et al., 1997), have been collected along dust events with a source region in northwestern $\mathrm{Sa}$ hara. Hence, these last results show further more that the differences in mineralogy between source regions are significant for the lower content minerals: smectite, kaolinite, quartz, and dolomite in accordance to Avila et al. (1997). It has also been mentioned that different $\mathrm{Ca} / \mathrm{Al}, \mathrm{Fe} / \mathrm{Ca}, \mathrm{K} / \mathrm{Ca}$, and $\mathrm{Si} / \mathrm{Al}$ ratios may be found at different collection sites. In fact, the ratio between two selected elements is dependent on the particle size distribution (Coude-Gaussen et al., 1987) and therefore can be affected by gravitational settling processes.

We believe that the results reported in this paper provide further data on the dependence of the particle properties on source regions and on the geographical site where have been collected, and may be useful to the scientific community since they contribute to document and understand the interaction of mineral aerosols with the environment. 
Acknowledgements. This work has partially been supported by the EARLINET Project, Environment Program of the European Union, under the contract No. EVR1-CT1999-40003. A. Tafuro has carried out this work with the support of a contract provided by the EARLINET Project. The air-mass back trajectories analysis was performed by the German Weather Service, by using the Interactive Data Analysis (IDL) code provided by I. Mattis (Institut fur Tropospharenforschung, leipzig, Germany). The radiosounding data of the Meteorological Station of Brindisi (Italy) have been provided by NOAA (http://raob.fsl.noaa.gov). The TOMS data have been made available by NASA (http://toms.gsfc.nasa.gov/aerosols/ aerosols.html). The authors would like to thank the SeaWiFS Project (Code 970.2) and the Goddard Earth Sciences Data and Information Services Center/Distributed Active Archive Center (Code 902) at the Goddard Space Flight Center, Greenbelt, MD 20771, for the production and distribution of these data, respectively. These activities are sponsored by NASA's Earth Science Enterprise.

\section{References}

Alpert. P., Neeman, B. U., and Shay-el, Y.: Climatological analysis of the Mediterranean cyclones using ECMWF data, Tellus, 42A, 65-77, 1990.

Avila, A.: I. Queralt-Mitjans and M. Alarcòn: Mineralogical composition of African dust delivered by red rains over the northeastern Spain, J. Geophys. Res, 102, 21 977-21 996, 1997.

Barnaba, F. and Gobbi, G. P.: Lidar estimation of tropospheric aerosol extinction, surface area and volume: Maritime and desert-dust cases, J. Geophys. Res., 106, 3005-3018, 2001.

Bergametti, G., Dutot, L., Buat-Menard, P., and Remoudaki, E.: Seasonal variability of the elemental composition of atmospheric aerosol particles over the northwestern Mediterranean, Tellus, 41B, 553-561, 1989a.

Bergametti, G., Gomes, L., Remoudaki, E., Desbois, M., Martin, D., and Buat-Menard, P.: Present-day transport and deposition patterns of African dust to the nortwestern Mediterranean. In Paleoclimatology and paleometeorology: modern and past patterns of global atmospheric transport, eds. M. Leinen and M. Sarnthein, 227-252, KLuwer, Dordrecht, 1989b.

Chester, R., Baxter, G. G., Behairy, A. K. A., Connor, K., Cross, D., Elderfield, H., and Padgham, R. C.: Soil-sized aeolian dust from the lower troposphere of eastern Mediterranean Sea, Marine Geology, 24, 201-217, 1977.

Chester, R., Nimmo, M., Alarcon, M., and Corcoran, P.: The chemical character of the western Mediterranean aerosol, Water Pollution Research Reports, 28, 495-504, 1992.

Chiapello, I., Bergametti, G., Chatenet, B., Bousquet, P., Dulac, F., and Santos Soares, E.: Origin of African dust transported over the northeastern tropical Atlantic, J. Geophys. Res, 102, 13 701$13709,1997$.

Coude-Gaussen G., Rognon, P., Bergametti, G., Gomes, L., Strauss, B., Gros, J. M., and Le Coustumer, M. N.: Saharan dust on Fuerteventura Island (Canaries): chemical and mineralogical characteristics, air mass trajectories, and probable sources, J. Geophys. Res., 92, 9753-9771, 1987.

d'Almeida, G. A.: A model for Saharan dust transport, Journal of Climate and Applied Meteorology, 25, 903-916, 1986.

Ganor, E.: The composition of clay minerals transported to Israel as indicators of Saharan dust emission, Atmosph. Environm., 25A,
12, 2657-2664, 1991.

Ganor, E. and Foner, H. A.: The Mineralogical and Chemical Properties and the Behavior of Aeolian Saharan Dust over Israel, in The Impact of Desert Dust Across the Mediterranean, Oristano 4-7 October, 24 (abs), 1995.

Gobbi, G. P., Barnaba, F., Van Dingenen, R., Putaud, J. P., Mircea, M., and Facchini, M. C.: Lidar and in situ observations of continental and Saharan aerosol: closure analysis of particles optical and physical properties, Atmos. Chem. Phys. Discuss., 3, 445477, 2003.

Goldstein, J. I. and Yakowitz, H.: Practical scanning electron microscopy, Plenum Press New York, 1975.

Guerzoni, S., Molinaroli, E., and Chester, R.: Saharan dust inputs to the western Mediterranean Sea: depositional patterns, geochemistry and sedimentological implications, Deep-Sea Research II, 44, 3-4, 631-654, 1997.

Hamonou, E., Chazette, P., Balis, D., Dulac, F., Schneider, X., Galani, E., Ancellet, G., and Papayannis, A.: Characterization of the vertical structure of Sahara dust export to the Mediterranean basin, J. Geophys. Res., 104, 22 257-22 270, 1999.

Herman, J. R., Bhartia, P. K., Torres, O., Hsu, C., Seftor, C., and Celarier, E.: Global distribution of UV-absorbing aerosols from Nimbus 7/TOMS data, J. Geophys. Res., 102, 16911-16922, 1997.

Hooker, S. B., Esaias, W., Feldman, G., Gregg, W., and McClain, C. R.: "An overview of the SeaWiFs and ocean color," Vol. 1 of SeaWiFS Technical Report Series, NASA Tech. Memo. 104566, NASA Goddard Space Center, Greenbelt, Md., 1992.

Kottmeier, C. and Fay, B.: Trajectories in the antartic lower troposphere, J. Geophys. Res., 105, 10 947-10 959, 1998.

IPCC (Intergovernmental Panel on Climate Change): Climate Change 2001. The scientific basis. Eds. J. T. Houghton, Y. Ding, M. Nogua, D. Griggs, P. Vander Linden, K. Maskell, Cambridge Univ. Press, Cambridge, UK and New York, NY, USA, 2001.

Levin, Z. and Lindberg, J. D.: Size distribution, chemical composition and optical properties of urban and desert aerosols in Israel, J. Geophys. Res., 84, 6941-6950, 1979.

Levin, Z., Joseph, J. H., and Mekler, Y.: Properties of Sharav (Khamsin) dust - comparison of optical and direct sampling data, J. Atmosph. Sci., 37, 882-891, 1980.

Ma, C. J., Kasahara, M., Holler, R., and Kamiya, T.: Characteristics of single particles sampled in Japan during the Asian dust-storm period, Atmosph. Environm., 35, 2707-2714, 2001.

Mattis, I., Ansmann, A., Muller, D., Wandinger, U., and Althausen, D.: Dual-wavelength Raman lidar observations of the extinctionto-backscatter ratio of Saharan dust, Geophys. Res. Lett., 29, No. 9, 20.1-20.4, 2002.

Mishchenko, M. I., Travis, L. D., Kahn, R. A., and West, R. A.: Modeling phase functions for dustlike tropospheric aerosols using a shape mixture of randomly oriented polydisperse spheroids, J. Geophys. Res., 102, 16 831-16847, 1997.

Molinaroli, E.: Mineralogical characterization of Saharan dust with a view to its final destination in Mediterranean sediments, in “The Impact of Desert Dust Across the Mediterranean", S. Guerzoni and R. Chester (eds.), Kluwer Academic Publishers, printed in the Netherlands, 153-162, 1996.

Molinaroli, E., Guerzoni, S., and Rampazzo, G.: Contribution of Saharan dust to the central Mediterranean basin, Geological Society of America, Special paper 284, 1993. 
Moulin, C., Lambert C. E., Dayan, U., Masson, V., Ramonet, M., Bousquet, P., Legrand, M., Balkanski, Y., J., Guelle, W., Marticorena, B., Bergametti, G., and Dulac, F.: Satellite climatology of African dust transport in the Mediterranean atmosphere, J. Geophys. Res., 103, 13 137-13 144, 1998.

Nazar, A. M., Silva, F. A., and Amman, J. J.: Image processing for particle characterization, Materials Characterization, 36, 165173, 1996.

Paoletti, L., De Bernardis, B., and Diociaiuti, D.: Physico-chemical characterization of the inhable particulate matter (PM10) in an urban area: an analysis of the seasonal trend, The Science of the Total Environment, 292, 265-275, 2002.

Podczeck, F., Rahman, S. R., and Newton, J. M.: Evaluation of a standardized procedure to assess the shape of pellets using image analysis, Intern. Journal of Pharmaceutics, 192, 123-138, 1999.

Prodi, F. and Fea, G.: A case of transport and deposition of Sahara dust over the Italian Peninsula and Southern Europe, J. Geophys. Res., 84C, 6951-6960, 1979.

Prospero, J. M.: Arid regions as sources of mineral aerosols in the marine atmosphere, Geological Society of America, SP 186, 7185, 1981.

Prospero, J. M.: Long-term measurements of the transport of African mineral dust to the southeastern United States: Implications for regional air quality, J. Geophys. Res., 104, 15917$15927,1999$.

Prospero, J. M., Ginoux, P., Torres, O., Nicholson, S., E., and Gill, T. E.: Environmental characterization of global sources of atmospheric soil dust identified with the Nimbus 7 Total Ozone Mapping Spectrometer (TOMS) absorbing aerosol product, Review of Geophys., 40, 2-1-2-31, 2002.
Raes F., Van Dingenen, R., Vignati, E., Wilson, J., Putaud, J. P., Seinfeld, J. H., and Adams, P.: Formation and cycling of aerosols in the global troposphere, Atmosph. Environm., 34, 4215-4240, 2000.

Ro, C. U., Oh, R. Y., Kim, H. K., Chun, Y., Osan, J., de Hoog, J., and Van Grieken, R.: Chemical speciation of individual atmospheric particles using low-Z electron probe X-ray microanalysis: characterizing "Asian Dust" deposited with rainwater in Seoul, Korea, Atmosph. Environm., 35, 4995-5005, 2001.

Salisbury, J. W., Walter, L. S., Vergo, N., and D'Aria, D. M.: Infrared (2.1-25 $\mathrm{mum}$ ) Spectra of Minerals, John Hopkins University Press, Baltimore/London, 1991.

Sokolik, I. N. and Toon, O. B.: Incorporation of mineralogical composition into models of the radiative properties of mineral aerosol from UV to IR wavelength, J. Geophys. Res., 104, 9423-9444, 1999.

Stohl, A.: Computation, accuracy and application of trajectories a review and bibliography, Atmosph. Environm., 32, 947-966, 1998.

Talbot, R. W., Harriss, C., Browell, E. V., Gregory, G. L., Sebacher, D. I., and Beck, S. M.: Distribution and geochemistry of aerosols in the tropical North Atlantic troposphere: Relation to Saharan dust, J. Geophys. Res., 91, 5173-5182, 1986.

Tegen, I. and Fung, I.: Contribution to the atmospheric mineral aerosol load from land surface modification, J. Geophys. Res., 100, 18707-18726, 1995. 